\title{
Exploring the practice of feedback to students
}

\section{Abstract}

Feedback to students is a vital but relatively under-researched area. An analysis is presented of practice in a complex modular business programme. Attention is drawn to the difficulty of such analysis, but three ways of looking at the text are presented: by modality, by area of concern and by developmental content. A conversational form of feedback with a focus on 'implied development' is identified and placed in the context of Bernstein's notion of an 'invisible pedagogy'. Such a focus may disadvantage students and the importance of reflection on feedback in the context of knowledge claims at both the module and the programme level is stressed.

Keywords: assessment; feedback

\section{Introduction}

How many departments, for example, routinely analyse the written comments on students' work to see the extent to which lecturers are engaging with the substance of the intellectual argument presented or simply commenting on presentation and format? (Atkins, 1995: 27) 
The research reported on in this article had its genesis in an attempt to carry out the sort of analysis recommended by Atkins, albeit for a faculty rather than a department. In the course of the discussion that follows we will see that the attempt casts some doubt on the possibility of 'routinely' carrying out such an exercise. This article presents three interpretations of a set of feedback comments that covered a range of staff in a large and complex undergraduate business programme. In one sense, the findings might be thought to be 'disappointing'. That is, no large claims are made in this article; rather, the main finding from the research is the rather modest one that, despite clear examples of individual poor practice, most academics in this sample were trying their best, often in difficult circumstances, to give helpful feedback to their students. This in itself might be thought to be a useful corrective to the picture which sometimes seems to emerge from the 'advice' literature, which does have a tendency to focus on poor practice in order to make its case for improvement. What this also suggests is that such advice needs to focus not only on improvements in individual practice, but also on issues such as programme design. Given the increasing focus on a more strategic approach to issues of assessment, with departments being encouraged to develop clear guidance on issues such as feedback to students, it may be useful to draw upon an account of practice to suggest areas that such guidance might cover (Rust, 2002; Mutch, 2002a).

The evidence gathered is used to suggest patterns that seem to emerge, rather than to claim any statistical representativeness. The main focus of the article is on the textual analysis of these comments, that is, on the practice of a sample of academics as represented in their words. Of course, what the student recipients do with these words is crucial. Students may ignore the written feedback and concentrate on the grades,. Or they may take a different message from the feedback from that which the member 
of staff intended to convey. In more formal terms, the giving of feedback on assessed coursework is a social practice that demands attention to not only the text but also to the conditions of production, distribution and reception (Fairclough, 1995; Lea and Street, 1998). However, our research is conditioned by questions of practicality. The research was designed to look at academic practice in the light of critical, but anecdotal, comment by a variety of stakeholders, who complained that feedback was informative or too brief. Looking at such questions is relatively easy, as we will explore; looking at student responses is altogether a more complex issue. This article, then, has a limited scope and the conclusions must therefore be provisional and tentative. These conclusions suggest how the research might be taken further, but also suggest that feedback to students is not just a matter of individual practice, crucial though that is. From the research emerged the notion of 'implied developmental' feedback and the conclusions suggest that feedback practices need to be placed in the context of careful course design. That is, well meaning attempts to engage in conversation with students may founder if students have not been prepared to engage with such comments. Again, these observations are designed to suggest further avenues for exploration, rather than being offered as a definitive approach.

The context for this research is a large Business School in a post-1992 UK university. The Business School has extensive undergraduate provision, comprising six full-time degrees ranging from general business studies to more specialised areas such as business information systems, as well as part time and 'top-up' variants. These degrees are part of a modular scheme in which, particularly in the first year, students study common modules drawn from the four academic departments of the School. These departments comprise some 120 academic staff and some 3,000 students are 
enrolled on the undergraduate degrees at any one time. These degrees are assessed in different ways depending on the focus of the degree and the combination of modules taken, but a rough estimate would be of a 60/40 split between assessed coursework and examinations. It can be seen that a considerable volume of coursework is assessed in any academic year, giving rise to concern about the nature and quality of feedback on the part of a range of stakeholders, from students to external examiners. From the internal quality mechanisms of the School, a number of perspectives emerge. The student focus is on the extent and timing of comments on assessments, with concerns that these do not allow them to develop. From a staff perspective, there is a concern that students fail to act upon feedback, to the extent sometimes of not collecting their assessed work. External examiners point to the need for more sustained commentary to support marks. It was perceived that more evidence was needed in order to assess such concerns. This evidence is discussed further below, but an emerging pattern was that, on the whole, staff were taking their responsibilities in this area seriously. This seemed to be at some variance with the impression gained from the 'advice' literature.

\section{The literature on assessment feedback}

Assessment as a whole is a subject that is attracting more attention and is the subject of a number of recent publications (Brown, Bull and Pendlebury, 1997; Miller, Imrie and Cox, 1998; Freeman and Lewis, 1998). The following comments are going to rather critical of this literature as it relates to feedback. However, this is not to reject the many useful things that they say about assessment in general. Rather, the argument is that their enthusiastic advocacy could prove to be counter-productive if not more firmly based on substantive evidence. The evidence presented is often 
sparse, the reasons for presenting it are rarely spelt out and such as are given seem to relate more to the memorability of the example than to any structured approach. To take one example,

Miller, Imrie and Cox comment, 'Lecturers are often criticized for failing to provide sufficient feedback on the quality of a student's work or the level of attainment reached by the student'(1998: 113). This cannot be denied, but to what extent are such criticisms representative of general academic practice? The problem for such writers is that there is relatively little research material in this area. What there is tends to be based on small or undeclared samples of student work.

For example, Falchikov's (1995) work, although its main focus is on peer, rather than tutor, feedback is based on a content analysis on work from 13 students. Clearly, one would be wrong to condemn such small samples in the context of exploratory work, but we need to be clear that much of the evidence in this area is based on small samples. Ivanič, Clark and Rimmershaw (2000: 47) present nine examples that 'comprise a selection of responses by tutors to students' writing from those we have collected from two academic settings'. The criteria for selection appear to be that the responses stand out, rather than that they are in any way 'representative', but broad assertions are made on the basis on such a sample. They contend, for example, that students' self-esteem has the potential to be damaged by feedback (Ivanič, Clark and Rimmershaw, 2000: 60-1). However, the limited evidence available on the reception of feedback would suggest that matters are more complex. The existing level of selfesteem, argues Young (2000), conditions how students will receive any comments, however carefully these are phrased by the tutor. Again, Thorpe's (2000) discussion of tutor feedback on student reflection is based on an unquantified sample of scripts based on institutional sampling procedures. Her interesting assessments are based on 
comments like 'Most tutors in the first year made very few comments' (Thorpe, 2000: 85). A use of small samples and the use of the word 'frequently' in an unquantified fashion is also seen in the very valuable and suggestive work of Lea and Street (1998).

This failure of Lea and Street to be clear about sample size draws exasperated comment from Hartley and Chesworth (2000). Their response is to carry out questionnaire-based research on student perceptions of feedback practice, whilst recognising some limitations with this. For the purpose of this article, their approach takes us away from the content of feedback. An alternative approach is to take a more systematic approach to the evidence presented in the texts that tutors produce, and this is the one adopted in this paper. In this, it builds on the reflections on qualitative research as evidence by Sayer (1992) and Oakley (2000). However, whilst such analysis might suggest new categories, no data are approached without previous theoretical grounding and it is worth a brief discussion of the perspectives that inform this endeavour. It is grounded in the notion that feedback, like writing in general, is a social practice. In this the paper draws upon Lea and Street's (1998: 159) notions of 'academic literacies', the idea that we need to view 'student learning and writing as issues at the level of epistemology and identities rather than skill or socialisation.' In analysing such social practices we need to be aware that they involve a number of levels. For Fairclough (1995), critical discourse analysis needs to examine the text, textual practices and social practice. The second involves the conditions of the production, distribution and reproduction of texts. The third is the way such production links to the broader context. In this paper, the main focus is on the text, but we need to be constantly aware that this is produced and received in particular 
contexts. The adequate study of such contexts, as exemplified by the insightful work of Pardoe (2000), is beyond the scope of this research, but needs to be constantly borne in mind.

In examining our evidence, therefore, we need some measure of the sort of language being used. The unit of analysis is likely to be the complete sentence, for this gives a context to particular words. However, we need a little more precision than that offered by the sort of literary analysis offered above. Just how often are particular linguistic practices used? We can find vivid examples of good and bad practice, but are these representative? Just how much feedback is being given and how does it relate to marks? Such questions demand that we take a more structured approach, utilising codings that try to draw out patterns from the evidence. It is such an approach that is taken to this data, but first we need to explain how it was obtained.

\section{Sample and approach}

Coursework in the Business School takes many forms. Whilst the issue of feedback on such experiences as oral presentations is important and interesting, the focus here is on written coursework. The reason is one of access to evidence, in the form of the cover sheets that students must attach to their work. These multi-part forms serve a number of functions. They act as a receipt for students, a means of identifying markers and contain a signed declaration by the student related to codes on assessment and plagiarism. For the purpose of this research, the most important function is that they contain a space for feedback to the student. One copy of this is returned with the work and one filed in the office. This filed copy seemed to offer a 
valuable source of insight into feedback practices. These sheets were then sampled, with two sheets being extracted for each module archive that was available. This gave a final selection of 63 feedback sheets from 33 modules. To this initial sample should be added a further sample of 59 sheets from 6 modules that had been examined by external examiners. This further sample was selected because of comments observed in the initial sample such as 'see report for further comments'. To anticipate the discussion below, it could be the case that the significant feedback was to be found on the scripts rather than on the feedback sheet. Clearly, most work had been returned to students and so could not be checked. However, some of that reviewed by external examiners had been retained and this added a further nine members of staff to the sample. At 44 this represents nearly half of the 105 fulltime members of the School's teaching staff (Clearly, a weakness with this approach that has to be recognised is the failure to examine practice amongst part-time members of staff.) The final sample covered work from 11 degrees across all levels, although with a bias towards final year work (because of the external sample). It should be made clear at this stage that it is not being claimed that this process has produced a 'representative' sample. Indeed, this would be a formidable job in the conditions of scale and complexity that characterise contemporary higher education. Similarly, the process of coding should not give us the illusion of 'scientific' results. Rather, the results are designed to direct our attention to aspects of practice that might appear to have some significance beyond the immediate salience of particular expressions. Clearly, this yields material that could form the basis of further research projects. The conclusions drawn from the interpretation presented below should be seen as provisional and tentative. However, it is suggested that the approach employed does attempt to go beyond a purely literary 
approach and as such it may suggest potential avenues of exploration for others interested in this area.

The main focus of this article is on the content of comments, but a few words on the scale of these comments might be informative. Some staff did indeed write very little on the feedback sheets. A range of 5 words to 104 words for the initial sample and 7 to 129 for the external sample raises some questions about what can be usefully said at the bottom end of the range. However, only fifteen percent of the sample comments were below 30 words, which suggests that the majority practice is not to simply write on a few words. A more detailed analysis suggests that the cause of variation is not related to either level of study or mark obtained, although there is a weak pattern of rather fewer comments on final year work with good marks. This suggests that variation is down to individual practice, not to the nature of the material. Of course such a conclusion could be grossly unfair to those who write copious comments on scripts and a short summary on the feedback sheet. This was the reason for examining those scripts sent to the external examiner and so retained in the School's archives. The suggestion from comparing comments on the feedback sheets to those on scripts suggests that those who write more feedback are also likely to write more on scripts. Again, we would suggest that this is a feature of individual practice as much as of the nature of the work. Whilst this indicates that feedback is more than that which is contained on the sheets, there does seem to be some support for the notion that those who give more feedback give it in all forms. However, we have said nothing about the content of this feedback. A few well-chosen words, after all, may be much more valuable than dozens of illegible comments! We turn, therefore, to look at what the feedback sheets say. 


\section{Reading words}

As indicated above, the sample selected gave a substantial volume of words for analysis. The issue then became one of finding a suitable way to approach this text. Whilst a simple reading of this material might throw up vivid examples, the issue of representativeness needed to be resolved. One result of such a simple reading was that the use of 'final language' (Brown and Smith, 1997: 13) such as 'good' or 'poor' as standalone comments was limited. Whilst there were some very short responses, as already discussed, these were relatively rare and even here it was rare for adjectives simply to be used on their own. The sentence therefore seemed the appropriate unit of analysis. The challenge now was to find an appropriate classification scheme.

One approach is to examine the sort of issues that tutors were commenting on. Miller, Imrie and Cox (1998:112) for example give a list of 'six areas in which markers' comments may be useful to students.' They go on to comment that

Unfortunately some of us, when marking essays, put all of our efforts into the correction of spelling errors and grammatical faults (each of which needs correction), ignoring the far more important issues such as those listed.

The areas indicated are expressed in negative terms and, as we will see below, many comments are formatted in positive ways. Accordingly, the first level of analysis was to code the sentences in the areas suggested by these headings. What we find is that the concentration is not, as suggested, on issues of presentation. (It should be noted 
that this analysis includes failures of referencing under this heading. For many tutors, of course, referencing has an intimate relationship with structuring and argument and is far from being a 'technical' issue). The focus of the external sample, as one might expect, tends to be skewed more towards understanding than knowledge.

Take in Table I about here

This form of analysis does seem to cast some doubt again on the sweeping generalisations of the advice literature. A different approach is called for, one that addresses the tone of the statements, regardless of the issue commented on.

Lea and Street (1998: 169) comment 'Tutor comments frequently take the form of what we call categorical modality, using imperatives and assertions, with little mitigation or qualification.' They contrast this to more 'mitigated' forms of modality, which they suggest might create a different relationship between tutor and student, one less dependent on the tutor's perceived expert power. If we examine our sample through this lens we do indeed get a picture of the general use of categorical statements, with $75 \%$ of the text units being coded in this form, a picture than is even sharper on first year work. However, this observation suggests a a need to be cautious about the automatic assumption 'categorical = bad', and not just because it may relate to the perceived quality of the work. One point is that such analysis ignores the grammatical specificity of what Halliday (1994) terms 'little texts'. These are, in Halliday's (1994: 392) words, texts that 'have to achieve quite a lot in ...very limited space' and so 'tend to have their own grammar', grammar that tends to produce stripped down statements that appear to be categorical. In other words, we need to pay more attention to the conditions of production. Given mass higher education, it is perhaps unsurprising that feedback is often terse; perhaps a 
solution here is not the 'reform' of direct feedback, but the use of alternative methods? Further, we have to take care, as noted above, about the impacts of a more mitigated style. This can be positive for those who understand how to receive it. However, for many this could be seen to blur the boundaries that clearer messages might give. We will return to this point later, but it relates to a third way of looking at our evidence. This suggests that a category of 'implied development' is important in tutor's practice.

This 'third way' starts from the simple dualism of 'positive/negative', given advice such as 'find positive elements to comment on first and at the finish if at all possible' (Brown and Smith, 1997: 12). Within this, it seemed necessary to distinguish between text units that seemed to just comment on the work and that which suggested some development. An example of the sort of material coded under the first would be 'A well written and clearly structured essay' for positive work and 'A disappointing report' for negative. By contrast, the following would be coded as 'positive developmental':

While you address the arguments and critiques on both sides you might have developed or even illustrated some of these further with cases or some more substantial material.

However, whilst engaging in coding it seemed that this simple four-fold division was not sufficient. One issue was that of the 'factual' statement, where the material covered was simply restated. For example, the following seems to be substantially a précis of the material covered: 
You highlight how the EU's limited authority, Treaty ambiguities, inconsistent rules applications and the determination of many member governments to use aid in one form or another contribute to an incoherent application of state aid rules.

This is taken further in two (and therefore) rare instances in which work is commented on as if the student is not present: 'This is a very clear and well written account of $x$ 's experience in the module.' Such 'factual' statements seem to fit with a 'traditional' form of academic discourse that is all but absent from the sample examined. Rather, the dominant tone is that of the 'conversational', with many commentaries addressing students by name and containing requests such as ' $\mathrm{Can}$ we have a chat!' Such comments were coded as 'neutral' in this analysis.

As will be seen below, these 'factual' and 'neutral' elements are quite a small element. Of rather more significance are those elements coded as 'implied developmental'. Language analysts would point to the vital importance of the absent in textual analysis. That is, if all text creation is a matter of selection and choice, what is left unsaid may be as significant as that which is said. Of course, to fully analyse this we have to have some access to what might be said. In this case, such access is only partially possible in the case of the external sample, where we have a copy of the original work that is being commented on. What we don't have, of course, is access to the reasoning behind what has been said. It could be said here that we are into issues of subject expertise and judgement. To comment fully on what had been selected for comment would require a fresh assessment of the work, and that is not the purpose of 
this article. However, what we can perhaps comment on is the way in which statements about student work can be thought to have developmental implications. For example, here is a positive statement that might, from a student perspective, be seen as a 'closed' comment, not requiring further action: 'Evidence of using some good, basic sources.' However, another reading of this might suggest that the student needs to go on to more advanced sources. (We might also think that 'evidence' might not be as direct as 'you have used' and so might in itself suggest that the use of the sources could have been clearer.) Here is a 'negative' example which also links to a significant trope employed, that of the dichotomy between surface and depth (or descriptive-critical): 'Too much of your word count was used on descriptive content.' To those familiar and comfortable with the language this is indeed clear and suggests a development needed: to redress the balance and spend more time on analysis. However, especially for the weaker student, this intention might not be clear. This assertion clearly would need work with students on how feedback might be received, but such statements seemed to occur with sufficient frequency to merit separate categorisation.

There is one further category that emerged from the coding exercise. Again, it was an infrequent one, but one that deserves discrete attention. Here is an example:

The issue of recent performance merits consideration perhaps as confirming (or not as the case may be) customer dissatisfaction?

In the context of the feedback this emerges not so much as an area for development but as a musing by the marker, responding in conversational fashion to the work 
presented (cf. similar comments by Ivanič, Clark and Rimmershaw, 2000: 57).

Context is important here, but there are a limited number of statements that have this quality and so have been coded as 'conversation'. In some characterisations, (e.g. that of Laurillard (1993)) this is what higher education ought to be aiming towards.

If we take the results of this coding exercise, bearing in mind that the boundaries between these categories are blurred and subject to debate and interpretation, we can look first of all at whether, on balance, comments are broadly positive or negative. In the initial sample the balance favours the positive (51\%) over the negative (42\%) with the balance being neutral. In the external sample the position is reversed, with $53 \%$ of comments being broadly negative. We have to remember here that the external sample has a greater representation of marks at lower levels; as we will see, there is a clear relationship between level of work and type of comment. However, overall there is almost a balance between the comments at $45 \%$ positive and $47 \%$ negative. If we relate these distinctions to level of marks, then we get the picture shown in Table II for negative comments:

Take in Table II about here

This might be what we would expect; what might be of more importance is the balance of comments within these categories. Table III gives the results of coding for both samples in categories that combine the positive and negative:

Take in Table III about here

The broad comparability either shows a consistency of coding or a consistency of practice - or both! Again, one would want to be cautious about interpretation, but these figures do seem to suggest an overall predominance of developmental 
comments if we sum the two categories. $54.35 \%$ of the initial sample and $51.46 \%$ of the external sample were coded in this way. It then becomes of interest to see if this balance is maintained at different levels. In particular, are markers suggesting how good work can be developed further and are they giving clear guidance to those whose work is below standard? The following table shows for each sample, by grade, the number and percentage of total comments that were developmental and then the percentage of these developmental comments that were direct, rather than implied. Take in Table IV about here

What this does suggest is that markers are rather less likely to suggest developmental actions to those who they consider excellent, especially at final year - which is perhaps not surprising. Of more interest might be the reduction at the bottom end of those comments that are directly developmental. This has to be seen in context - on this analysis, markers are indicating to poorer students how they might improve work and at least half of this advice is given in direct form. However, there does seem to be a tendency to give poorer students advice that we might hypothesise that they might be poorly equipped to deal with.

This might be seen if we return to the language of surface and depth. Two examples drawn from different essays might illustrate this:

A more critical/analytical approach would help you develop more depth in your arguments. $(45 \%)$

This is a well-written thorough albeit descriptive approach to the question and shows you have researched the topic and gained an appreciation of some of the issues. $(55 \%)$ 
The same issues might be expressed in slightly different terms. For example, the injunction to 'Find a model (E.g. you cited Buchanan \& Boddy on 1st page) and be systematic in discussing it' (mark 35\%) could also be seen as suggesting a way of moving from description to analysis. The issue is the way in which this feedback is received and acted on, which returns us to notions of the capacity of students from a diversity of backgrounds and experience to recognise and respond appropriately to feedback.

\section{Conclusions: feedback and programme design}

This discussion of feedback allows us to draw a number of conclusions relating to practice at a number of levels. What we have suggested is that the practice examined does attempt to give students feedback on a range of aspects of their work. It does not, in general, simply give perfunctory feedback and it does address its feedback to a full range of performance, with a bias towards issues of knowledge and understanding. However, this feedback is often presented in categorical terms, which might have an impact on its reception by students. Clearly, a full exploration of this contention requires a different research programme that focuses on how students receive and respond to feedback. What could be of more significance in this reception process is the notion of feedback that contains 'implied development'. Comments which employ this approach might, it could be hypothesised, be of value only to those who recognise what the implied developments are. Such a hypothesis might usefully be tested by further research, research which might find the application of Bernstein's work on education and social class useful (Mutch, 2002b). This literature adds some support to 
the arguments presented by Lea and Street (1998), which suggest that what is 'clear' to staff may be far from 'clear' to students (See also Stierer, 2001). They point in particular to differences in what counts as knowledge and argument between discipline areas, something which might also relate to feedback. This is supported by moves towards independent and lifelong learning. That is, in employing a 'conversational' style of feedback assumptions are made about the extent to which students will recognise what is being said. Such a style might be adopted in the sincere belief that it will enhance the reception of feedback; it could be that, for some students it does just the opposite. Clearly such assertions would need to be tested empirically, but they are made to emphasise the importance of seeing assessment feedback as a social practice. In this sense, the focus on individual practice might be misplaced. We can recommend that tutors ought to give clear feedback (both physically and linguistically!) but by itself this would be to focus only on a small part of the picture. In this, Lea and Street's (1998) critique of modality fails to focus on the conditions of production. Because of this, it is likely to be received with exasperation by harassed academics.

What we might suggest is central as far as individual academics are concerned is reflection on the purpose of feedback. If this is seen to be about the development and enhancement of learning, then ways can be sought to overcome the conditions of production and distribution that produce categorical statements. The widespread use of Web pages and electronic mail, for example, offer useful vehicles for the provision of collective, generic feedback. This can be taken further to use the model of Frequently Asked Questions to bolster feedback during rather than after the assessment process. However, by themselves this is to ignore the conditions of 
reception. This is where designing in opportunities for reflection on feedback is important. These need in turn to be linked, as Lea and Street (1998) argue, to a central concern with what it is to know in the subject or discipline concerned. All of this can be done at the level of the individual module. However, it will be much more powerful if reinforced by a programme design that places reflection on feedback at its heart.

This can have important structural consequences, as reflection on feedback needs careful attention to time. If it is to be effective, it needs to be part of a developmental process and, further, one that is reinforced laterally during a student's studies. For example, in one of the programmes that comprised the provision in the sample reviewed, attempts were being made in some modules to engage with this question by building opportunities for feedback and reflection into module design. A first year module has a group debate and report. Students discuss the criteria for assessed presentations before the debate. They then receive collective feedback on their group performance in a timetabled session. They can then resubmit the report, taking into account the feedback on their first attempt. This is followed up by an individual session at which they are encouraged to reflect on feedback on assessments. A final year module on the same programme has students preparing several drafts of a group research paper. At each stage, students receive feedback on their drafts, which is then taken into account in the next revision. In this example, there is a gap in course design at the second year. What this might point to is the problems involved in such attempts. Of course, they can be seen as resource hungry, although this can be catered for by using time in a different fashion - there are, for example, few lectures on these modules. However, the demands here are not only on time, but also often on academics' emotional reserves. Receiving feedback and discussing it face to face can 
be a challenging process which, without careful management, can turn into confrontation. Again, this suggests a need for a supportive context, a need which suggests that programmes need to ensure that they aim to make clear to students the way that knowledge is created, validated and tested in their area. This is likely to involve debate and contention on the part of both students and staff, which is likely to uncomfortable at times. However, without such debate, feedback, even of the most carefully crafted type, could be fated to be misunderstood and ignored.

In turn, there is the need for support at a wider level. Rust (2002: 156) suggests that departments should provide 'explicit guidelines on giving effective feedback'. The argument of this article is that such guidelines should not be just at the level of individual practice, but should also be at the level of module and programme design. It is crucial that feedback is seen as a developmental activity, but to focus just on individual practice might be to miss out on the full range of conditions which make for the effective use of feedback. Above all, this relates to the capacity of students to make sense of and apply feedback in order to further their learning.

\section{References}

Atkins, M. (1995) What Should We be Asessing? in: P. Knight (Ed) Assessment for Learning in Higher Education London: Kogan Page, pp. 25-34.

Boud, D. (1995) Assessment and Learning: Contradictory or Complementary, in: P.Knight (Ed) Assessment for Learning in Higher Education, London: Kogan Page, pp. 35-48.

Brown, S. and Knight, P. (1994) Assessment in Higher Education, London: Kogan Page. 
Brown, S. and Smith, B. (1997) Getting to Grips with Assessment, Birmingham: SEDA.

Brown, G., Bull, J. and Pendlebury, M. (1997) Assessing Student Learning in Higher Education, London: Routledge.

Brown, S. and Glasner A. (eds) (1999) Assessment Matters in Higher Education.

Choosing and Using Diverse Approaches, Buckingham: SRHE and Open University Press.

Fairclough, N. (1995) Critical Discourse Analysis, London: Longman.

Falchikov, N. (1995) Improving Feedback To and From Students, in: P. Knight (Ed) Assessment for Learning in Higher Education, London: Kogan Page, pp. 157-166.

Freeman, R. and Lewis, R. (1998) Planning and Implementing Assessment, London: Kogan Page.

Halliday, M. A. (1994) An Introduction to Functional Grammar, London: Arnold. Hartley, J. and Chegworth, K. (2000) Qualitative and Quantitative Methods in Research on Essay Writing: No One Way, Journal of Further and Higher Education 24(1): pp. 15-24.

Ivanic, R., Clark, R. and Rimmershaw, R. (2000) What Am I Supposed to Make of This? The Messages Conveyed to Students by Tutors' Written Comments, in: M. Lea and B. Stierer (Eds) Student Writing in Higher Education, Buckingham: Open University Press and SRHE, pp. 47-66.

Knight, P. (1995) Assessment for Learning in Higher Education, London, Kogan Page.

Laurillard, D. (1993) Rethinking University Teaching. A Framework for the Effective Use of Educational Technology, London, Routledge. 
Lea, M. and Street, B. (1998) Student Writing in Higher Education: an academic literacies approach, Studies in Higher Eduaction, 23(2): pp. 157-172.

Lea, M. and Stierer, B. (Eds) (2000) Student Writing in Higher Education: New Contexts, Buckingham: Open University Press and SRHE.

Miller, A., Imrie, B. and Cox, K. (1998) Student Assessment in Higher Education: a handbook for assessing performance, London, Kogan Page.

Mutch, A (2002a) Thinking Strategically About Assessment, Assessment and Evaluation in Higher Education,

Mutch, A (2002b) Applying the Ideas of Bernstein to In-company Management Education, Management Learning, 33(2), 181-196.

Oakley, A. (2000) Experiments in Knowing: Gender and Method in the Social Sciences, Cambridge: Polity.

Pardoe, S. (2000) A Question of Attribution: The Indeterminacy of 'Learning from Experience', in: M. Lea and B. Stierer (Eds) Student Writing in Higher Education, Buckingham: Open University Press and SRHE pp. 125-146.

Rust, C. (2002) The impact of assessment on student learning: how can research literature practically help to inform the development of departmemntal assessment strategies and learner-centred assessment practices? Active Learning in Higher Education, 3(2), pp. 145-158.

Sayer, A. (1992) Method in Social Science: a Realist Approach, London, Routledge.

Stierer, B. (2000) Schoolteachers as Students: Academic Literacy and the

Construction of Professional Knowledge within Master's Courses in Education, in: M.

Lea and B. Stierer (Eds) Student Writing in Higher Education, Buckingham: Open University Press and SRHE, pp. 179-195. 
Thorpe, M. (2000) Encouraging students to reflect as part of the assignment process: student responses and tutor feedback, Active Learning, 1(1): pp. 79-92. Young, P. (2000) 'I Might As Well Give Up': self-esteem and mature students' feelings about feedback on assignments, Journal of Further and Higher Education 24(3): pp. 409-418. 